\title{
Reflexive autonomy
}

Autonomy is central to being a professional. The individual's capacity to make rational, informed decisions without coercion is the basic tenet of professionalism; or, at least, the notion of professionalism which has prevailed since the eighteenth century, deriving from Kant's moral philosophy, where someone determines a course of action on the basis of moral duty and ethical behaviour.

The making of ethical professional decisions is central to Graham Farmer's paper in this issue of arq (pp. 106-119). Farmer reviews three student self-build projects, characterising the attitudes to technology underlying each one. They illustrate, he argues, that design is inherently a process of making ethical choices. Choosing a technology, he suggests, is 'choosing a form of life that necessarily favours living in one way over another'.

Radical professional autonomy has been celebrated, in post-structuralist architectural theory, as an opportunity for critique. Particularly in paper projects - like those of Peter Eisenman and Brodsky \& Utkin - architects are freed from supposedly mundane concerns to pursue forms of social and political criticism. Carolyn Fahey explores Lebbeus Woods' famous polemical projects for Berlin and Sarajevo (pp. 131-137). Woods' claims for radical autonomy, she argues, tend to mask an attitude where 'the social' and 'the political' become generic ideas rather than sets of real concerns shared by real people. Robert Saliba, meanwhile, reviews design studios run at the American University of Beirut after the Hezbollah-Israeli war of 2006 (pp. 167-176). For him, conventional professionalism encourages 'a value-free, conciliatory and humanitarian attitude toward local political conflict' which, he argues like Fahey, tends to rationalise design ideas in relation to generic 'economic, functional and aesthetic considerations'. He advocates an alternative position, tested by one studio where students designed from their own political standpoints, embracing controversy as a way to articulate differences towards architectural solutions. Studio projects - which were afforded autonomy by their location in an architecture school - became an opportunity to question the mechanisms of professional autonomy.

The arena of architectural competitions is often imagined as a neutral space within which the skills of autonomous architects and practices can be straightforwardly judged against each other. This is, Torsten Schmiedeknecht shows, a simplification. He evaluates competition practices in Germany, centred on the journal Wettbewerbe Aktuell (pp. 177-187). There is evidence, he demonstrates, that the journal has not been just a neutral conduit for 
publishing competition results, it also influenced architects' conceptual approach to competitions and the architecture expected of them'.

Ute Poerschke reviews architects' fascination with the idea that particular materials have their own autonomous logic (pp. 149-156). 'What does the call to use wood as wood or stone as stone mean?', she asks. Developing Poerschke's fascination with what it means for a material to be itself, David Dernie recalls 'crystal imagination' in the late nineteenth-century culture of Belgian Symbolism. The idea of the crystal became decisive to the conception of glass architectures in the twentieth century (pp. 157-166), he argues. For 'late Romantic writers, artists and architects', 'the depths of mirror, translucent glass and polished stone captured the soul and released a world of dreams'.

Autonomy may be both a liberation and a curse for professionals. It equips them with freedom of action but also, potentially, distances them from the people for whom they act. Scholars in Science and Technology Studies talk about 'reflexive autonomy'. They refer to actors in the scientific field whose autonomous behaviour remains outward-looking and generous. These are ethical professionals, it is suggested, whose professionalism does not exist within its own bubble but instead reflects the world around and is able to influence that world. In diverse ways, the authors in this issue of arq make a case for reflexive autonomy in architecture - among architects, materials and practices.

THE EDITORS 